\title{
Impact of the method of exposure in total hip arthroplasty on balancing ability in response to sudden unidirectional perturbation in the first six months of the postoperative period
}

\author{
Gergely Holnapy ${ }^{\mathrm{a}}$, Rita M. Kiss ${ }^{\mathrm{b}, *}$ \\ ${ }^{a}$ Semmelweis University, Department of Orthopaedics, Hungary \\ ${ }^{\mathrm{b}}$ Budapest University of Technology and Economics, Department of Structures, Müegyetem rkp. 3, H-1111 Budapest, Hungary
}

\section{A R T I C L E I N F O}

Article history:

Received 10 July 2012

Received in revised form 10 January 2013

Accepted 10 January 2013

\section{Keywords:}

Balance

Balancing ability after sudden

Unilateral perturbation

Total hip arthroplasty

\begin{abstract}
A B S T R A C T
Introduction and objective: Total hip arthroplasty affects 3-5\% of the elderly population. Therefore, the effectiveness of surgery and the ensuing rehabilitation is of great significance. This study investigated balancing ability in response to sudden unidirectional perturbation changes during the first 6 months of the postoperative period with respect to different methods of joint exposure during the operation (antero-lateral, direct-lateral and posterior to preserve the joint capsule). Our hypothesis is that the results may provide a tool to improve the rehabilitation procedures.

Materials and methods: The dynamic balancing ability of 25 patients with direct-lateral exposure, 22 with antero-lateral exposure and 25 with posterior exposure during a total hip arthroplasty was examined using ultrasound-based provocation tests prior to and at 6 weeks, 12 weeks and 6 months after total hip arthroplasty. The control group was represented by 45 healthy subjects of identical age. The dynamic balancing ability after unidirectional perturbation was characterised by Lehr's damping ratio calculated from the results of tests performed with the patient standing on both limbs, standing on the affected limb and standing on the non-affected limb.

Results: In the case of direct-lateral and antero-lateral exposure, Lehr's damping ratio significantly decreased compared to the preoperative values at 6 weeks postoperatively, but it increased steadily afterwards. Lehr's damping ratio while standing on the affected limb was significantly lower - even at 6 months postoperatively - than that of the control group. In the case of posterior exposure, Lehr's damping ratio continuously increased in the postoperative period and corresponded to that of the control group at 6 months after total hip arthroplasty.

Discussion and conclusion: For patients operated on using direct-lateral and antero-lateral exposure methods, the dynamic balancing ability continuously improved in the first 6 months of the postoperative period, but the dynamic balancing ability of the affected limb differed from that of the control group. In the case of posterior exposure to preserve the joint capsule the dynamic balancing ability evaluated a more rapidly compared to the other two exposure methods. There was no significant difference in the balancing ability of the control group at 6 months after total hip arthroplasty with posterior exposure. The increasing range of joint motion, muscle development, and the development of the dynamic balancing ability should be taken into account when compiling rehabilitation protocols. Differences related to the method of exposure should be considered when developing the dynamic balancing ability and abandoning therapeutic aids.
\end{abstract}

(c) 2013 Elsevier Ltd. All rights reserved.

\section{Introduction}

As a consequence of the ageing of the population, the frequency of hip osteoarthritis has gradually increased in recent decades, and a similar trend is expected for the coming decades. In a worldwide comparison, hip osteoarthritis can be considered one of the major

\footnotetext{
* Corresponding author. Tel.: +36 1463 1738; fax: +36 14631751 .

E-mail address: kissrit@t-online.hu (R.M. Kiss).
}

causes of limited motion. Hip osteoarthritis affects nearly $1.5 \%$ of the entire population and $15-2 \%$ of the elderly population over 65 years of age. Conservative and surgical treatment is a long-term and considerable task of major national health significance. In 3$5 \%$ of the elderly population, hip osteoarthritis is serious enough that it is reasonable to implant a hip endoprosthesis (Felson and Zhang, 1998).

Pain is relieved and functional abilities are partly restored by total hip arthroplasty (THA) (Jones et al., 2000; Wylde et al., 
2009), but gait patterns are significantly modified during the postoperative period (Bennett et al., 2007, 2008; Foucher et al., 1998, 2007; Kiss and Illyés, 2012; Mont et al., 2007; Vogt et al., 2003, 2004). It has been shown in earlier research that at half a year and 1 year after THA, the perception of the joint position corresponds to that of healthy subjects (Grigg et al., 1973; Karanjia and Ferguson, 1983). A presumable reason for this is that the state of the hip joint surface and of the joint capsule has a much smaller impact on the perception of the joint position (Grigg et al., 1973) than the state of the articular ligaments and periarticular muscles (Ishii et al., 1999). As long as 18 weeks after THA, the two sides are still loaded asymmetrically (Belaid et al., 2007; Madeira et al., 1998). In a double-leg stance, the backward, forward and lateral motions of the centre of pressure (COP) begin to decrease from the 12th day postoperatively (Belaid et al., 2007), and at 6 months after THA, they do not differ from the control group (Nantel et al., 2008; TrudelleJackson et al., 2002). The values measured while standing on the affected side increase until the 12th week, and the values do not differ significantly from the preoperative values until the 18th week after THA (Madeira et al., 1998). The back and forth and lateral motions of the COP are significantly larger than in the control group, even at 1 year after surgery (Nantel et al., 2008; Trudelle-Jackson et al., 2002). Majewski et al. (2005) drew similar conclusions for body swings during gait.

Highly complex coordination is required to attempt to regain balance after a sudden impulse or change in direction, either from a static posture (standing or sitting) or during motion (walking or running) (Winter, 1995). In everyday life, people often encounter this phenomenon after being bumped into while walking or standing. The decreased equilibrium ability may also indicate an increased risk of falling (Robbins et al., 1989). Balancing ability after sudden perturbation can be characterised by Lehr's damping ratio $(D)$ determined from the provocation test (Kiss, 2011a). A decrease in Lehr's damping ratio represents a decrease in the balancing ability after a sudden perturbation (Kiss, 2011a). The results of previous research established that the balancing capacity after sudden perturbation in patients with hip osteoarthritis deteriorated compared with control subjects (Kiss, 2010).

To our knowledge, no study has examined the effects of the method of exposure in total hip arthroplasty on the balancing ability after sudden perturbation. The aim of this study was to specify the dynamic balancing ability in response to sudden unidirectional perturbation - modelled by ultrasound-based provocation tests - following different exposure methods during THA (antero-lateral - AL, direct-lateral - DL and posterior to preserve the joint capsule - P). For this purpose, ultrasound-based provocation tests (Kiss, 2011a) were conducted prior to and at 6 and 12 weeks and 6 months after THA. The Lehr's damping ratio characterising the dynamic balancing ability was compared with (a) Lehr's damping ratio in healthy subjects of the same age; (b) Lehr's damping ratio determined preoperatively and (c) Lehr's damping ratio determined in patients operated using different methods of exposure. The joint capsule and periarticular joints are affected differently depending on the method of exposure; consequently, the method of exposure in the case of total hip arthroplasty has a considerable impact on the spatial, temporal and angular parameters to characterise gait patterns (Kiss and Illyés, 2012). Therefore, it can be presumed that postoperative changes in the dynamic balancing ability will be different. If the method of exposure affects not only the gait parameter but also the dynamic balancing ability, it could be an important issue for the consideration of different surgical methods and their postoperative treatments.

\section{Subjects and method}

\subsection{Subjects}

Patients with severe hip osteoarthritis (OA) from an impact study of hip osteoarthritis were selected from patients at the Department of Orthopaedics of Semmelweis University. The inclusion and exclusion criteria are summarised in Table 1. Two-directional (antero-posterior and lateral) X-rays were taken of the subjects' hip joints; based on such radiological records, an expert radiologist ascertained that all the patients suffered from severe (KL grade 4) hip osteoarthritis according to the Kellgren-Lawrence (KL) score (Kellgren and Lawrence, 1957). The radiological records showed severe subchondral arthrostic lesions (subchondral cysts, calcification), as well as a narrowing of the articular space.

The 72 patients included in the investigation were divided into three groups according to the method of exposure of total hip arthroplasty. The 25 patients making up the first group were operated on by traditional direct-lateral (DL) exposure with the joint capsule removed; the 22 patients forming the second group were subjected to antero-lateral (AL) exposure, also with the joint capsule extirpated; and the 25 patients making up the third group were operated on by posterior $(\mathrm{P})$ exposure with the joint capsule preserved. The anthropometric data are summarised in Table 2. The patients were provided with the same preoperative and postoperative treatment (anaesthesia, pain relief); rehabilitation of all the patients was supervised on the basis of a previously arranged protocol by the same physiotherapist until the 12th week postoperatively.

Before the test, the dominant side was determined for each healthy participant using a balance recovery test. The perturbation was a nudge from the tester applied to the subject at the midpoint between the scapulae from directly behind the subject and sufficient to require the participant to respond by taking a step. The leg that the subject used to recover balance was considered the dominant leg for each of the three trials. This three-test sequence was the same for all subjects (Hoffman et al., 1998). In the patient groups, the dominant side was the healthy side, and the non-dominant side was the affected side prior to and after THA on basis of balance recovery test.

Table 2 summarises the demographic data for the 45 healthy elderly people making up the control group involved in the impact study of hip osteoarthritis (Kiss, 2010). The healthy controls had no history of osteoarthritis of the knee or hip joint, knee instability, or major lower extremity joint surgery. The controls also exhibited normal strength, a full range of motion of the lower extremities, and no neurological or balance deficiencies. Except for the existence of hip osteoarthritis, the inclusion and exclusion criteria corresponded to the criteria for the patient group (Table 1). As a result of the balance recovery test (Hoffman et al., 1998), the dominant

Table 1

Inclusion and exclusion criteria.

\begin{tabular}{ll}
\hline Inclusion criteria & Exclusion criteria \\
\hline $\begin{array}{c}\text { Unilateral hip arthritis as } \\
\text { evidenced by X-ray }\end{array}$ & $\begin{array}{l}\text { Any alteration, lesion or surgery affecting a } \\
\text { lower limb or the spine in the clinical } \\
\text { history }\end{array}$ \\
$\begin{array}{c}\text { Faculty of independent motion } \\
\text { (without aid) }\end{array}$ & $\begin{array}{l}\text { OA affecting any other joint (opposite hip } \\
\text { joint, bilateral knee joint) }\end{array}$ \\
$\begin{array}{c}\text { Ability to walk on a treadmill } \\
\text { at } 1.2 \mathrm{~m} / \mathrm{s} \text { speed for } 10 \mathrm{~min}\end{array}$ & $\begin{array}{l}\text { Neurological alterations (Parkinson's, } \\
\text { dementia, stroke, etc.), alterations affecting } \\
\text { balancing ability, vestibular alterations }\end{array}$ \\
Age between 55 and 65 years & $\begin{array}{l}\text { Uncontrolled, non-maintained } \\
\text { cardiovascular alterations } \\
\text { Vision correction over } \pm 5.0 \text { diopters }\end{array}$ \\
\hline
\end{tabular}


Table 2

Demographic data of the subjects.

\begin{tabular}{|c|c|c|c|c|c|c|c|c|}
\hline \multirow{2}{*}{$\begin{array}{l}\text { Features } \\
\text { Gender of subject }\end{array}$} & \multicolumn{2}{|c|}{ Control group } & \multicolumn{2}{|c|}{$\begin{array}{l}\text { Patients operated on with direct- } \\
\text { lateral (DL) exposure }\end{array}$} & \multicolumn{2}{|c|}{$\begin{array}{l}\text { Patients operated on with antero- } \\
\text { lateral (AL) exposure }\end{array}$} & \multicolumn{2}{|c|}{$\begin{array}{l}\text { Patients operated on with posterior }(\mathrm{P}) \\
\text { exposure to preserve joint capsule }\end{array}$} \\
\hline & Male & Female & Male & Female & Male & Female & Male & Female \\
\hline Number of cases, $N$ & 23 & 22 & 12 & 13 & 11 & 11 & 13 & 12 \\
\hline Age, years & $60.9 \pm 3.2$ & $60.4 \pm 4.1$ & $60.1 \pm 2.4$ & $59.9 \pm 3.4$ & $61.3 \pm 3.4$ & $62.1 \pm 2.4$ & $61.2 \pm 2.9$ & $60.8 \pm 3.0$ \\
\hline Body weight, kg & $70.4 \pm 9.8$ & $69.7 \pm 11.4$ & $86.5 \pm 11.4^{*}$ & $80.8 \pm 6.1^{*}$ & $88.6 \pm 7.8^{*}$ & $79.3 \pm 4.3^{*}$ & $89.5 \pm 8.2^{*}$ & $76.9 \pm 6.8^{*}$ \\
\hline Body height, cm & $170.4 \pm 5.8$ & $166.7 \pm 3.8$ & $169.7 \pm 6.8$ & $164.2 \pm 3.1$ & $170.1 \pm 5.4$ & $163.2 \pm 3.8$ & $169.4 \pm 5.6$ & $163.4 \pm 6.9$ \\
\hline BMI, $\mathrm{kg} / \mathrm{m}^{2}$ & $24.3 \pm 2.8$ & $25.3 \pm 2.4$ & $30.3 \pm 3.4^{*}$ & $30.1 \pm 3.1^{*}$ & $30.7 \pm 2.8^{*}$ & $29.8 \pm 3.3^{*}$ & $31.3 \pm 3.4^{*}$ & $28.9 \pm 2.7^{*}$ \\
\hline
\end{tabular}

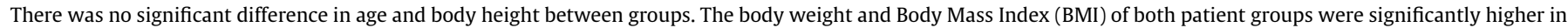
the patient groups than those of the control group.

side was the left side in 4 females and 6 males, and the right side was dominant in 18 females and 17 males.

Each subject examined was informed in writing about the risks and benefits of the study and given the opportunity to withdraw at any time; the subjects confirmed these actions by providing written informed consent. This study was authorised by the Science and Research Ethics Committee of Semmelweis University (111/ 2004).

\subsection{Method}

The dynamic balancing ability was characterised by ultrasoundbased provocation tests. Unidirectional sudden perturbation was modelled by a PosturoMed $\odot$ (Haider-Bioswing $\mathrm{GmbH}$, Weiden, Germany) therapeutic device (Boeer et al., 2010; Kiss, 2011a; Müller et al., 2004). In the present study, the motion of the suspended rigid plate of the PosturoMed $\odot$ therapeutic device was regulated by four springs, representing an easy test. The rigid plate was moved unidirectionally (medial and lateral direction of investigated person) in the horizontal plane. The fastening/provocation unit of the device (Fig. 1) was used for fixing the rigid plate suspended by springs after being dislodged from the central position, which is a medial-lateral displacement considered the dominant/ healthy limb. As the locking element was released, the rigid plate was returned to its original position, thus modelling a sudden perturbation. The subjects had to balance on the moving platform to regain their equilibrium in the given position. In this case, the rigid plate performed damped free oscillation; the damping corresponded to the subject's balancing ability.

Movements of the rigid plate were recorded by an ultrasoundbased ZEBRIS CMS-10 measurement system using individual active sensors (ZEBRIS, Medisintechnik GmbH, Isny, Germany) (Fig. 1). The measuring frequency was $100 \mathrm{~Hz}$. The rigid plate motion was recorded and stored using WinPosture (ZEBRIS, Isny, Germany) measurement control software. For healthy subjects, the testing

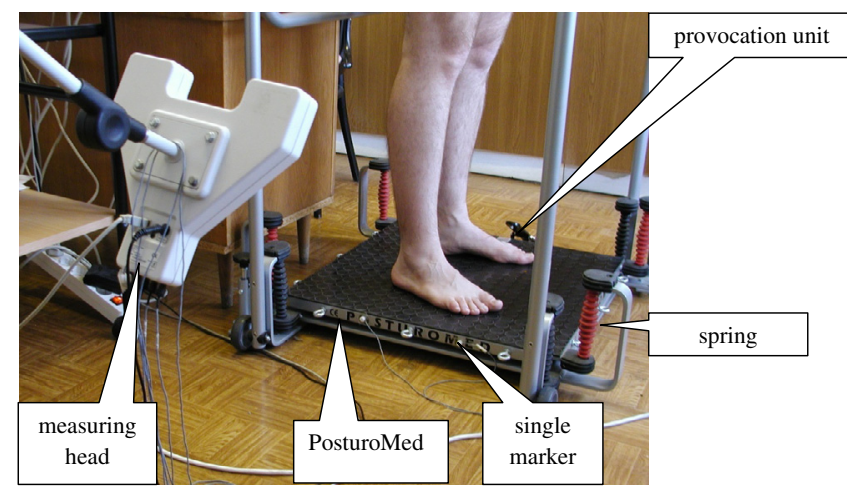

Fig. 1. Measurement arrangement for the ultrasound-based tests with sudden perturbation. was performed in the sequence of standing on both limbs, standing on the dominant limb, and standing on the non-dominant limb. The patients were tested standing on both limbs, standing on the non-affected limb, and standing on the affected limb. Each subject underwent 9 tests. The measurement details are included in Kiss (2011a).

The motion of the rigid plate parallel to the direction of displacement was damped oscillation, which could be modelled by the Lehr's damping ratio (Kiss, 2011a). Lehr's damping ratio can be calculated from the rigid plate motion (Kiss, 2011a) by

$D[\%]=\frac{\Lambda}{\sqrt{\Lambda^{2}+4 \pi^{2}}} * 100$,

where $\pi=$ is 3.14. $\Lambda$ is the logarithmic decrement, calculated as

$\Lambda_{i}=\frac{1}{i} \ln \frac{K_{0}}{K_{i}}$,

where $K_{0}$ is the amplitude at time $t=t_{0}$ and $K_{i}$ is the amplitude at time $t=t_{i \cdot 0}$ measured by the ultrasound-based system.

Previous studies (Kiss, 2011a) have shown that Lehr's damping ratio represents the balancing capacity in response to a sudden unidirectional perturbation. In healthy, young subjects standing on both limbs, Lehr's damping ratio is $5.20 \pm 0.25(D, \%)$, it is $5.09 \pm 0.23$ while standing on the dominant limb; and $4.17 \pm 0.14$ while standing on the non-dominant limb (Kiss, 2011a). In elderly subjects, Lehr's ratio depends not only on lateral dominance but also on age and gender (Kiss, 2011b). The values are summarised in the first two lines of Table 3. Kiss (2010) also established that Lehr's damping ratio was influenced by the severity of osteoarthritis in the hip joints.

Lehr's damping ratio was expressed as the mean and SD. The normality of the data distribution was assessed by the Kolmogorov-Smirnov test, and an F-test was used to assess the uniformity of standard deviations. The data received were analysed using a multi-variable ANOVA method, supplemented, if necessary, by a Tukey post hoc test. For the healthy group, the variables included the laterality (dominant and non-dominant) and subject gender (male or female). In the patient group, the variables included the laterality (non-affected and affected), subject gender (male or female), testing time (preoperatively, 6 weeks, 12 weeks and 6 months postoperatively) and the type of exposure (DL, AL, P). The data were processed using SPSS 14 software (SPSS, Chicago, IL, USA). Significance levels ( $p$ ) were set at 0.05 in each case.

\section{Results}

Previous studies (Kiss, 2011b) have shown that the Lehr's damping ratio to describe the dynamic balancing capacity is affected by the subjects' age and gender. The control group members and patient group members were selected to provide a narrow age range in our study (Table 1 ) so that the impact of age would not 
Table 3

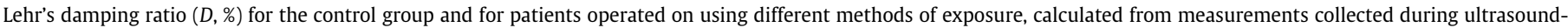
based tests with sudden perturbation in the first 6 months of the postoperative period.

\begin{tabular}{|c|c|c|c|c|}
\hline & & \multicolumn{3}{|l|}{ Type of test } \\
\hline & & Double-leg stance & Stance on dominant/unaffected limb & Stance on non-dominant/affected limb \\
\hline Control group & & & & \\
\hline Males $N=23$ & & $4.65 \pm 0.33$ & $4.47 \pm 0.30$ & $2.90 \pm 0.39^{\mathrm{a}, \mathrm{b}}$ \\
\hline Females $N=22$ & & $4.99 \pm 0.29^{9}$ & $4.83 \pm 0.28^{g}$ & $3.41 \pm 0.31^{\mathrm{a}, \mathrm{b}, \mathrm{g}}$ \\
\hline $\begin{array}{l}D L \text { exposure } \\
\text { Males } N=12\end{array}$ & $\begin{array}{l}\text { Preop } \\
6 \text { weeks postop } \\
12 \text { weeks postop } \\
6 \text { months postop }\end{array}$ & $\begin{array}{l}3.40 \pm 0.55^{\mathrm{c}} \\
2.71 \pm 0.62^{\mathrm{c}, \mathrm{d}} \\
4.10 \pm 0.46^{\mathrm{c}, \mathrm{d}, \mathrm{e}} \\
4.47 \pm 0.27^{\mathrm{d}, \mathrm{e}, \mathrm{f}}\end{array}$ & $\begin{array}{l}3.01 \pm 0.60^{\mathrm{c}} \\
2.28 \pm 0.58^{\mathrm{c}, \mathrm{d}} \\
3.79 \pm 0.39^{\mathrm{c}, \mathrm{d}, \mathrm{e}} \\
4.35 \pm 0.24^{\mathrm{d}, \mathrm{e}, \mathrm{f}}\end{array}$ & $\begin{array}{l}1.35 \pm 0.71^{\mathrm{a}, \mathrm{b}, \mathrm{c}} \\
0.58 \pm 0.28^{\mathrm{a}, \mathrm{b}, \mathrm{c}, \mathrm{d}} \\
2.12 \pm 0.27^{\mathrm{a}, \mathrm{b}, \mathrm{c}, \mathrm{d}, \mathrm{e}} \\
2.40 \pm 0.22^{\mathrm{a}, \mathrm{b}, \mathrm{c}, \mathrm{d}, \mathrm{e}, \mathrm{f}}\end{array}$ \\
\hline Females $N=13$ & $\begin{array}{l}\text { Preop } \\
6 \text { weeks postop } \\
12 \text { weeks postop } \\
6 \text { months postop }\end{array}$ & $\begin{array}{l}3.49 \pm 0.50^{\mathrm{c}} \\
2.81 \pm 0.60^{\mathrm{c}, \mathrm{d}} \\
4.19 \pm 0.40^{\mathrm{c}, \mathrm{d}, \mathrm{e}} \\
4.79 \pm 0.31^{\mathrm{d}, \mathrm{g}, \mathrm{e}, \mathrm{f}}\end{array}$ & $\begin{array}{l}3.13 \pm 0.61^{\mathrm{c}} \\
2.27 \pm 0.57^{\mathrm{c}, \mathrm{d}} \\
3.98 \pm 0.35^{\mathrm{c}, \mathrm{d}, \mathrm{e}} \\
4.65 \pm 0.22^{\mathrm{d}, \mathrm{g}, \mathrm{e}, \mathrm{f}}\end{array}$ & $\begin{array}{l}1.39 \pm 0.75^{\mathrm{a}, \mathrm{b}, \mathrm{c}} \\
0.57 \pm 0.25^{\mathrm{a}, \mathrm{b}, \mathrm{c}, \mathrm{d}} \\
2.18 \pm 0.24^{\mathrm{a}, \mathrm{b}, \mathrm{c}, \mathrm{d}, \mathrm{e}} \\
2.39 \pm 0.27^{\mathrm{a}, \mathrm{b}, \mathrm{c}, \mathrm{d}, \mathrm{e}, \mathrm{f}}\end{array}$ \\
\hline $\begin{array}{l}\text { AL exposure } \\
\text { Males } N=11\end{array}$ & $\begin{array}{l}\text { Preop } \\
6 \text { weeks postop } \\
12 \text { weeks postop } \\
6 \text { months postop }\end{array}$ & $\begin{array}{l}3.45 \pm 0.52^{\mathrm{c}} \\
2.82 \pm 0.58^{\mathrm{c}, \mathrm{d}} \\
4.28 \pm 0.40^{\mathrm{c}, \mathrm{d}, \mathrm{e}} \\
4.49 \pm 0.25^{\mathrm{d,e}, \mathrm{f}}\end{array}$ & $\begin{array}{l}3.04 \pm 0.61^{\mathrm{c}} \\
2.59 \pm 0.51^{\mathrm{c}, \mathrm{d}} \\
3.91 \pm 0.31^{\mathrm{c}, \mathrm{d}, \mathrm{e}} \\
4.38 \pm 0.21^{\mathrm{d}, \mathrm{e}, \mathrm{f}}\end{array}$ & $\begin{array}{l}1.30 \pm 0.69^{\mathrm{a}, \mathrm{b}, \mathrm{c}} \\
0.65 \pm 0.27^{\mathrm{a}, \mathrm{b}, \mathrm{c}, \mathrm{d}} \\
2.19 \pm 0.25^{\mathrm{a}, \mathrm{b}, \mathrm{c}, \mathrm{d}, \mathrm{e}} \\
2.51 \pm 0.24^{\mathrm{a}, \mathrm{b}, \mathrm{c}, \mathrm{d}, \mathrm{e}, \mathrm{f}}\end{array}$ \\
\hline Females $N=11$ & $\begin{array}{l}\text { Preop } \\
6 \text { weeks postop } \\
12 \text { weeks postop } \\
6 \text { months postop }\end{array}$ & $\begin{array}{l}3.53 \pm 0.48^{\mathrm{c}} \\
2.74 \pm 0.55^{\mathrm{c}, \mathrm{d}} \\
4.35 \pm 0.35^{\mathrm{c}, \mathrm{d}, \mathrm{e}} \\
4.81 \pm 0.30^{\mathrm{d}, \mathrm{g}, \mathrm{e}, \mathrm{f}}\end{array}$ & $\begin{array}{l}3.12 \pm 0.59^{\mathrm{c}} \\
2.37 \pm 0.55^{\mathrm{c}, \mathrm{d}} \\
3.85 \pm 0.40^{\mathrm{c}, \mathrm{d}, \mathrm{e}} \\
4.70 \pm 0.25^{\mathrm{d}, \mathrm{e}, \mathrm{g,f}}\end{array}$ & $\begin{array}{l}1.45 \pm 0.72^{\mathrm{a}, \mathrm{b}, \mathrm{c}} \\
0.67 \pm 0.29^{\mathrm{a}, \mathrm{b}, \mathrm{c}, \mathrm{d}} \\
2.14 \pm 0.29^{\mathrm{a}, \mathrm{b}, \mathrm{c}, \mathrm{d}, \mathrm{e}} \\
2.48 \pm 0.31^{\mathrm{a}, \mathrm{b}, \mathrm{c}, \mathrm{d}, \mathrm{e}, \mathrm{f}}\end{array}$ \\
\hline $\begin{array}{l}P \text { exposure } \\
\text { Males } N=13\end{array}$ & $\begin{array}{l}\text { Preop } \\
6 \text { weeks postop } \\
12 \text { weeks postop } \\
6 \text { months postop }\end{array}$ & $\begin{array}{l}3.44 \pm 0.41^{\mathrm{c}} \\
3.72 \pm 0.30^{\mathrm{c}, \mathrm{d}, \mathrm{h}} \\
4.62 \pm 0.28^{\mathrm{d}, \mathrm{e}, \mathrm{g}, \mathrm{h}, \mathrm{i}} \\
4.73 \pm 0.25^{\mathrm{d}, \mathrm{e}, \mathrm{g}, \mathrm{h}, \mathrm{i}}\end{array}$ & $\begin{array}{l}2.97 \pm 0.48^{\mathrm{c}, \mathrm{d}} \\
3.65 \pm 0.32^{\mathrm{c}, \mathrm{d}, \mathrm{h}} \\
4.39 \pm 0.29^{\mathrm{d}, \mathrm{e}, \mathrm{h}, \mathrm{g}} \\
4.42 \pm 0.25^{\mathrm{d}, \mathrm{e}, \mathrm{h}, \mathrm{g}}\end{array}$ & $\begin{array}{l}1.41 \pm 0.67^{\mathrm{a}, \mathrm{b}, \mathrm{c}} \\
1.00 \pm 0.60^{\mathrm{a}, \mathrm{b}, \mathrm{c}, \mathrm{h}} \\
2.45 \pm 0.34^{\mathrm{a}, \mathrm{b}, \mathrm{b}, \mathrm{d}, \mathrm{e}, \mathrm{f}, \mathrm{h}} \\
2.79 \pm 0.20^{\mathrm{a}, \mathrm{b}, \mathrm{d}, \mathrm{e}, \mathrm{f}, \mathrm{h}}\end{array}$ \\
\hline Females $N=12$ & $\begin{array}{l}\text { Preop } \\
6 \text { weeks postop } \\
12 \text { weeks postop } \\
6 \text { months postop }\end{array}$ & $\begin{array}{l}3.58 \pm 0.39^{\mathrm{c}, \mathrm{d}} \\
3.79 \pm 0.35^{\mathrm{c}, \mathrm{d}, \mathrm{h}, \mathrm{i}} \\
4.87 \pm 0.31^{\mathrm{de}, \mathrm{e}, \mathrm{h}, \mathrm{h}, \mathrm{i}} \\
4.97 \pm 0.27^{\mathrm{d}, \mathrm{e}, \mathrm{g}, \mathrm{h}, \mathrm{i}}\end{array}$ & $\begin{array}{l}3.10 \pm 0.49^{\mathrm{c,d}} \\
3.72 \pm 0.35^{\mathrm{c}, \mathrm{d}, \mathrm{h}, \mathrm{i}} \\
4.70 \pm 0.34^{\mathrm{de}, \mathrm{g}, \mathrm{g}, \mathrm{h}, \mathrm{i}} \\
4.91 \pm 0.28^{\mathrm{d}, \mathrm{e}, \mathrm{g}, \mathrm{h}, \mathrm{i}}\end{array}$ & $\begin{array}{l}1.45 \pm 0.59^{\mathrm{a}, \mathrm{b}, \mathrm{c}} \\
1.09 \pm 0.58^{\mathrm{a}, \mathrm{b}, \mathrm{c}, \mathrm{h}, \mathrm{i}} \\
2.57 \pm 0.31^{\mathrm{a}, \mathrm{b}, \mathrm{b}, \mathrm{d}, \mathrm{e}, \mathrm{f}, \mathrm{g}, \mathrm{h}, \mathrm{i}} \\
3.04 \pm 0.28^{\mathrm{a}, \mathrm{b}, \mathrm{d}, \mathrm{e}, \mathrm{f}, \mathrm{g}, \mathrm{h}, \mathrm{i}}\end{array}$ \\
\hline
\end{tabular}

a Significant difference compared to the Lehr's damping ratio calculated from testing during a double-leg stance.

b Significant difference compared to the Lehr's damping ratio calculated while standing on the dominant/unaffected limb.

c Significant difference compared to the control group values.

d Significant difference compared to the preoperative values.

e Significant difference compared to the values measured at 6 weeks after THA.

f Significant difference compared to the values measured at 6 weeks after THA.

g Significant difference between males and females.

h Significant difference compared to DL exposure.

i Significant difference compared to AL exposure.

have to be taken into consideration for the evaluation of the results. All test results were analysed by gender.

The result of the post hoc power analysis was 0.93 . The F-test demonstrated the uniformity of the standard deviations, and the Kolmogorov-Smirnov test demonstrated a normal distribution. Lehr's damping ratios $(D, \%)$ determined from the motion of the rigid plate during the ultrasound-based sudden perturbation tests are summarised in Table 3.

In all three patient groups, there were no significant differences between Lehr's damping ratios determined during a double-leg stance and while standing on the dominant limb $(p>0.21)$ during the 6 months-long postoperative period (Table 3 ). This indicates that in the case of AL and DL exposure, the Lehr's damping ratio determined from the values measured 6 weeks after THA was significantly lower $(p<0.007)$ than Lehr's damping ratio calculated from preoperative values. However, afterwards, Lehr's damping ratio continuously increased. Nevertheless, Lehr's damping ratio at 6 months postoperatively was significantly lower $(p<0.01)$ than in the control group (Table 3 ). Lehr's damping ratio was not affected by the subjects' gender $(p>0.07)$ (Table 3$)$.

In cases that used posterior exposure to preserve the joint capsule, Lehr's damping ratio continuously increased during the postoperative period. At 12 weeks after THA, the values measured during a double-leg stance and while standing on the non-affected limb corresponded to those of the control group $(p>0.09)$, and Lehr's damping ratio in females was significantly higher than in males $(p<0.006)$ (Table 3). At 6 months after THA, Lehr's damping ratio measured while standing on the affected limb did not differ significantly from the control group values $(p>0.08)$, but the difference was significant between males and females $(p<0.04)$ (Table 3 ). Lehr's damping ratio for patients operated on using the posterior method to preserve the joint capsule was significantly higher compared to the values of the other two patient groups in the postoperative period $(p<0.01)$ (Table 3$)$.

\section{Discussion}

The goal of this study was to determine the impact of total hip arthroplasty of various exposures on balancing ability after sudden unidirectional perturbation. As demonstrated in earlier studies, static balancing ability during a double-leg stance improved from 12 days after THA (Belaid et al., 2007), and it did not differ from that of healthy subjects from 6 months after THA (Nantel et al., 2008; Trudelle-Jackson et al., 2002). With regard to measurements taken while standing on the affected limb, static balancing ability 
deteriorated until 12 weeks after THA and remained significantly worse than the static balancing capacity of the control group even 1 year after surgery (Nantel et al., 2008; Trudelle-Jackson et al., 2002). For patients operated on using DL exposure, the dynamic balancing ability during gait was worse than that in healthy subjects even 1 year after THA (Majewski et al., 2005). No data were found in the literature on the impact of total hip arthroplasty performed using different exposure methods on the dynamic balancing ability.

The control group data corresponded to earlier research results (Kiss, 2010, 2011b). In summary, Lehr's damping ratio determined from values measured while standing on the non-dominant limb was smaller than Lehr's damping ratio while standing on the dominant limb or with a double-leg stance (Fig. 2), meaning that the dynamic balancing ability was influenced by lateral dominance. Lehr's damping ratio was significantly higher in female subjects than in males for all three testing methods (Fig. 2). This gender difference was presumably due to differences in the anatomy and in the different degree of deterioration in the vestibular and somatosensory functions of males and females (Masui et al., 2005).

There was no significant difference between the three patient groups prior to THA, and the values of Lehr's damping ratio calculated using all three testing methods (standing on both limbs, on the affected limb and on the non-affected limb) were significantly smaller than Lehr's damping ratio in the controls (Table 3). These results corresponded to our earlier findings (Kiss, 2010). Lehr's damping ratio while standing on the affected side was significantly lower than that while standing on the non-affected limb or on both legs (Fig. 3), which confirmed the results of previous research (Kiss, 2010). The results of the present study also showed that the influence of gender disappeared in cases of severe hip osteoarthritis because there was no significant difference between Lehr's damping ratio determined for males and females (Fig. 3).

At 6 weeks after hip arthroplasty with DL and AL exposure, Lehr's damping ratio calculated using all the three testing methods significantly decreased, compared to the values determined prior to surgery (Figs. 4 and 5). The results obtained for patients who received direct-lateral exposure confirmed the earlier findings of stabilometry testing because the static balancing ability also decreased in the early postoperative period (Belaid et al., 2007; Madeira et al., 1998). Presumably, the reason for this was that the joint capsule was extirpated during the DL and AL exposure (Freeman, 1965). Lehr's damping ratio continuously increased from the 6th week until 6 months postoperatively (Figs. 4 and 5). At 6 months after THA, Lehr's damping ratio determined during standing on both limbs and standing on the non-affected limb reached the normal value of the controls (Figs. 4 and 5). This result corresponded to previously published stance stability test results (Majewski et al.,

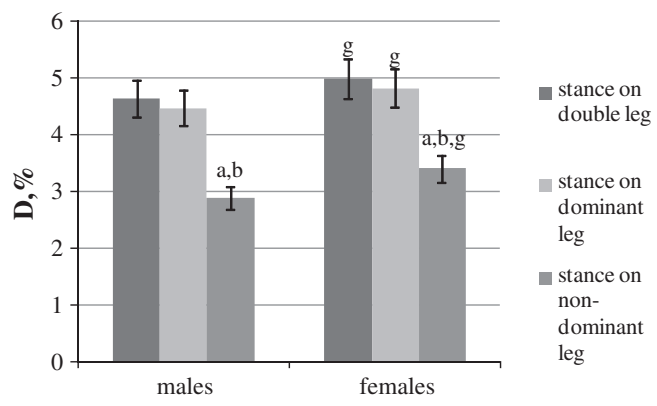

Fig. 2. Lehr's damping ratio $(D, \%)$ of the control group calculated from data collected through ultrasound-based tests with sudden perturbation. a - significant difference compared to Lehr's damping ratio calculated during a double-leg stance; b - significant difference compared to Lehr's damping ratio calculated while on the dominant leg; $\mathrm{g}$ - significant difference between males and females.

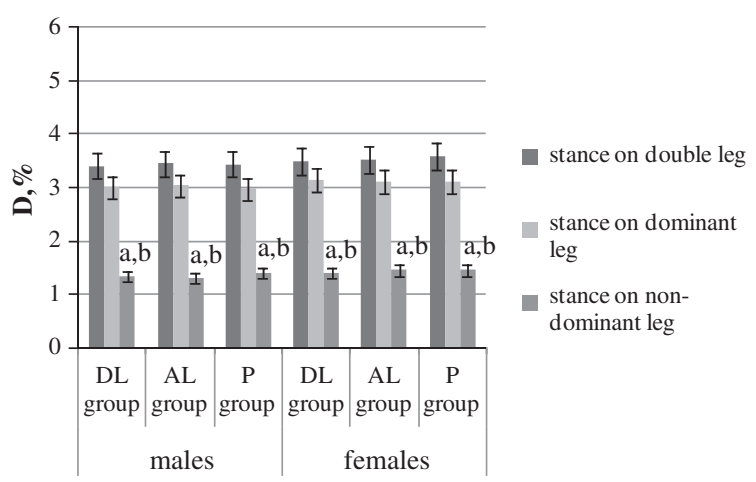

Fig. 3. Lehr's damping ratio $(D, \%)$ of patients operated on using different methods of exposure, calculated from measurement collected during ultrasound-based tests with sudden perturbation prior to THA. a - significant difference compared to Lehr's damping ratio calculated during a double-leg stance; b - significant difference compared to Lehr's damping ratio calculated while standing on the dominant leg.

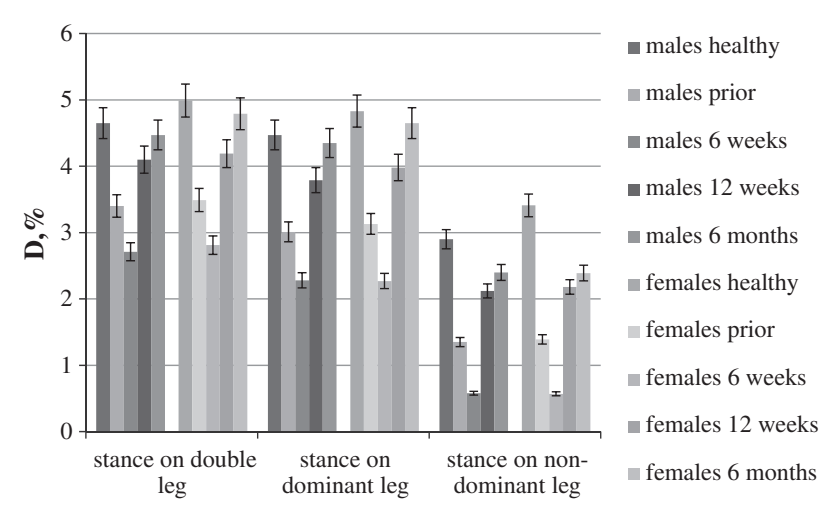

Fig. 4. Lehr's damping ratio $(D, \%)$ for the control group and for patients operated on using a direct-lateral (DL) method of exposure, calculated from data collected during ultrasound-based tests with sudden perturbation in the first 6 months of the postoperative period.

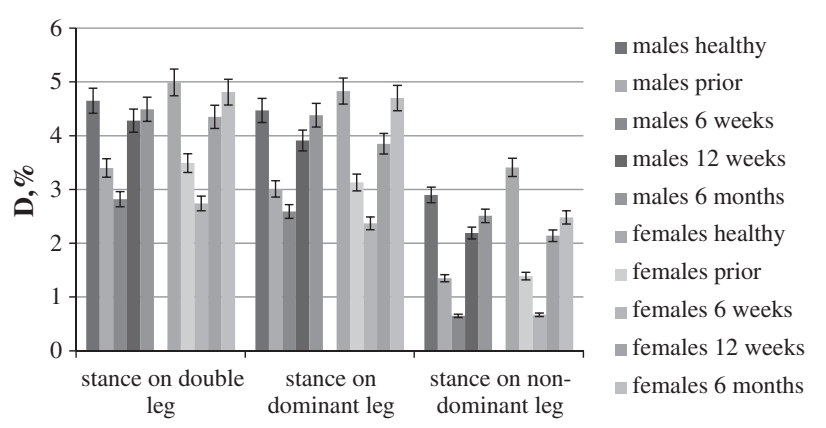

Fig. 5. Lehr's damping ratio $(D, \%)$ for the control group and for patients operated on using an antero-lateral ( $\mathrm{AL}$ ) method of exposure, calculated from measurements collected during ultrasound-based tests with sudden perturbation in the first 6 months of the postoperative period.

2005; Nantel et al., 2008; Trudelle-Jackson et al., 2002). When standing on the affected limb, the compensation effect of the non-affected limb was excluded. In this case, the balancing ability of the affected limb could be examined. Lehr's damping ratio while standing on the affected limb differed significantly from the control group (Figs. 4 and 5). The results showed that the balancing ability gradually improved in the first 6 months of the postoperative period, but it failed to reach that of control group (Figs. 4 and 5). Trudelle-Jackson et al. (2002) reached a similar conclusion 
based on pressure centre motion analysis during standing on the affected limb; the gait (spatial, temporal and angular) parameters on the affected side were significantly different from the values of the control group (Kiss and Illyés, 2012).

A possible explanation for the deterioration of gait parameters and balancing capacity could be that the muscles were unable to assume the role of the joint capsule. A deterioration in balancing ability also indicated an increased risk of falling (Nevitt et al., 1989) coupled with lower levels of adaptation to changes in external circumstances compared to healthy subjects (Robbins et al., 1989).

For patients with posterior exposure to preserve the joint capsule, Lehr's damping ratio calculated from all three testing methods were significantly higher during the postoperative period ( 6 weeks, 12 weeks and 6 months after THA) compared to the values determined prior to THA (Fig. 6). Lehr's damping ratio calculated from the values measured during a double-leg stance and while standing on the non-affected limb did not differ from the control group values at 12 weeks after THA. Furthermore, Lehr's damping ratio calculated from the values measured during standing on the affected limb did not differ from the control group values at 6 months after THA (Fig. 6). These results differed from the results of Trudelle-Jackson et al. (2002), who only examined patients operated on with the direct-lateral exposure method. This confirmed our assumption that in contrast to sensing the position of the joint (Grigg et al., 1973; Karanjia and Ferguson, 1983), the condition of the joint capsule considerably influenced the balancing ability. In the case of postero-lateral exposure, Nallegowda et al. (2003) found that 8 months after THA, the results of stabilometry testing conducted with the eyes open did not differ significantly from the control group, even when the tests were performed on a plate with sinusoidal motion. The gait parameters in patients who underwent THA by posterior exposure did not show significant differences at 6 months after THA compared to controls (Kiss and Illyés, 2012).

Comparison of Lehr's damping ratio in the three patients group showed that for patients with posterior exposure to preserve the joint capsule, the Lehr's damping ratio calculated using all three testing methods was significantly higher during the postoperative period than in the other two patient groups (DL and AL patient groups) (Table 3 ). These results suggested that the joint capsule played a decisive role in the quality of dynamic balancing ability. The results also showed that from the 6th month of the postoperative period, the risk of falling was already reduced in the case of patients who underwent total hip arthroplasty using the posterior exposure method to preserve the joint capsule.

The limitation of the present study is that the dynamic balancing ability was analysed only during the first 6 months of the postoperative period. Muscle activity was not measured during testing. Future investigations should address these issues as well.

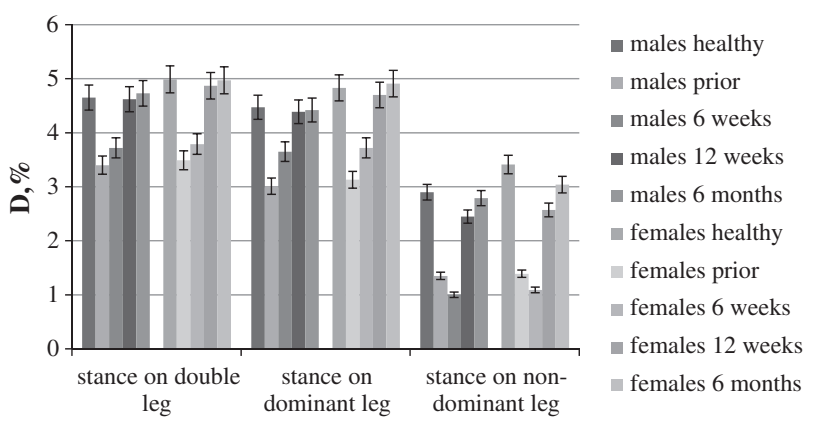

Fig. 6. Lehr's damping ratio $(D, \%)$ for the control group and for patients operated on using a posterior $(\mathrm{P})$ method of exposure, calculated from measurements collected during ultrasound-based tests with sudden perturbation in the first 6 months of the postoperative period.
In addition to increasing the joint motion and developing muscles, the development of dynamic balancing ability should also be taken into account when compiling rehabilitation protocols. Differences related to the method of exposure should be considered when developing the dynamic balancing ability and abandoning therapeutic aids.

In summary, it should be noted that the stabilometry tests are relatively simple, while balancing after sudden changes in direction requires complex coordination (Winter, 1995). The provocation test characterised by the dynamic balancing capacity after a sudden perturbation gives more specific information about the balancing capacity than the results of stabilometry. It could be stated that the dynamic balancing ability of patients operated on with DL and AL exposure continuously improved during the first 6 months of the postoperative period; however, the balancing ability of the affected limb differed from that of the control group. The dynamic balancing ability improved more quickly with a posterior exposure if either of the other two approaches was used. The provocation test could be used efficiently during the postoperative rehabilitation phase. Furthermore, it could be used to monitor the stages of rehabilitation to facilitate physiotherapy activities.

\section{Acknowledgements}

This project is supported by the Hungarian Scientific Fund K083650. The author wishes to express her thanks to the radiologist Katalin Köllö for her assistance in the evaluation of the radiographic images and to the orthopaedists Zoltán Bejek, Árpád Illyés, and Ákos Pethes for their assistance with the measurements.

\section{References}

Belaid D, Rougier P, Lamotte D, Cantaloube S, Duchamp J, Dierick F. Clinical and posturographic comparison of patients with recent total hip arthroplasty. Rev Chirurgie Orthopéd Reparat l'Appareil Moteur 2007;93:171-80.

Bennett D, Ogonda L, Ellitt D, Humphreys L, Lawlor M, Beverland D. Comparison of immediate postoperative walking ability in patients receiving minimally invasive and standard-incision hip arthroplasty. J Arthroplasty 2007;22:490-5.

Bennett D, Humphreys L, O'Brain S, Kelly C, Orr JF, Beverland DE. Gait kinematics of age-stratified hip replacement patients - a large scale, long-term follow-up study. Gait Post 2008;28:194-200.

Boeer J, Mueller O, Krauss I, Haupt G, Horstmann T. Zuverlässigkeitsprüfung eines Messverfahrens zur Charakterisierung des Standverhaltens und Quantifizierung des Balancevermögens auf einer instabilen Plattform (PosturoMed). Sportverletz Sportsc 2010;24:40-5.

Felson DT, Zhang Y. An update on the epidemiology of knee and hip osteoarthritis with a view to prevention. Arthritis Rheum 1998;41:1343-55.

Foucher KC, Hurwitz DE, Soomekh D, Andriacchi TP, Rosenberg AG, Galante JO. Factors influencing variation in gait adaptations after total hip replacement. Gait Post 1998;7:159.

Foucher KC, Hurwitz DE, Wimmer ME. Preoperative gait adaptations persist one year after surgery in clinically well-functioning total hip replacement patients. J Biomech 2007;40:767-74.

Freeman M. Treatment of rupture of the lateral ligament of the ankle. J Bone Joint Surg Br 1965;47:661-8.

Grigg P, Finerman GA, Riley LH. Joint-position sense after total hip replacement. J Bone Joint Surg AM 1973;55:1016-25.

Hoffman M, Schrader J, Applegate T, Koceja T. Unilateral postural control of the functionally dominant and nondominant extremities of healthy subjects. J Athlet Train 1998;33:319-22.

Ishii Y, Tojo T, Terajima K, Terashima S, Bechtold JE. Intracapsular components do not change hip proprioception. J Bone Joint Surg Br 1999;81B:345-8.

Jones CA, Voaklander DC, Johnston DW, Suarey-Almazor ME. Health related quality of life outcomes after total hip and knee arthroplasties in a community based population. J Rheumatol 2000;27:1745-52.

Karanjia PN, Ferguson JH. Passive joint position sense after total hip replacement surgery. Ann Neurol 1983;13:654-7.

Kellgren JH, Lawrence JS. Radiological assessment of osteoarthrosis. Ann Rheum Dis 1957; 16:494-502.

Kiss RM. Effect of the degree of hip osteoarthritis on equilibrium ability after sudden changes in direction. J Electromyogr Kinesiol 2010;20:1052-7.

Kiss RM. A new parameter for characterizing balancing ability on an unstable oscillatory platform. Med Eng Phys 2011a;33:1160-6.

Kiss RM. Influence factors of balancing capacity at healthy elderly subjects. In: Morrison B, editor. Proceedings of the 6th IASTED international conference on biomechanics, November 7-9, 2011b, Pittsburgh, USA. p. 61-6. 
Kiss RM, Illyés Á. Comparison of gait parameters in patients following total hip arthroplasty with a direct-lateral or antero-lateral surgical approach. Human Movem Sci 2012;31:1302-16.

Madeira F, Sergio J, Videira D, Videira M, Colaco C. Postural behavior in total hip arthroplasty. In: Lacour $\mathrm{M}$, editor. Posture et equilibre, pathologies, viellissement, strategies, modelisation. Montpellier: Sauramps Medical; 1998. p. $43-50$.

Majewski M, Bishoff-Ferrari HA, Gruneberg C, Dick W, Allum JHJ. Improvements in balance after total hip replacement. J Bone Joint Surg Br 2005;87B:1337-43.

Masui T, Hasegawa Y, Matsuyama Y, Sakano S, Kawasaki M, Suzuki S. Gender differences in platform measure of balance in rural community-dwelling elders. Arch Gerontol Geriatr 2005;41:201-9.

Mont MA, Seyler TM, Ragland PS, Starr R, Erhart J, Bhave A. Gait analysis of patients with resurfacing hip arthroplasty compared with hip osteoarthritis and standard total hip arthroplasty. J Arthroplasty 2007;22:100-8.

Müller O, Günther M, Krauß I, Horstmann T. Physikalische Charakterisierung des Therapiegerätes Poturomed als Meßgerät - Vorstellung eines Verfahrens zur Quantifizierung des Balancevermögens. Biomed Tech 2004;49:56-60.

Nallegowda M, Singh U, Bhan S, Wadhwa S, Handa G, Dwivedi SN. Balance and gait in total hip replacement: a pilot study. Am J Phys Med Rehab 2003;82:669-77.

Nantel J, Termoz N, Centomo H, Lavigne M, Vendittoli PA, Prince F. Postural balance during quite standing in patients with total hip arthroplasty and surface replacement arthroplasty. Clin Biomech 2008;23:402-7.

Nevitt MC, Cummings SR, Kidd S, Black D. Risk factor for recurrent nonsyncopal falls: a prospective study. J Am Med Assoc 1989;261:2663-8.

Robbins AS, Rubenstein LZ, Josephson KR, Schulman BL, Osterweil D, Fine G. Predictors of falls among elderly people. Results of two population-based studies. Arch Intern Med 1989;149:1628-33.

Trudelle-Jackson E, Emerson R, Smith S. Outcomes of total hip arthroplasty: a study of patients 1 year post surgery. J Orthopaed Sports Phys Ther 2002;32:260-7.

Vogt L, Brettmann K, Pfeifer K, Banzer W. Walking patterns of hip arthriplasty patients: some observation on the medio-lateral excursions of the trunk. Disab Rehab 2003;25:309-17.

Vogt L, Banzer W, Pfeifer K, Galm R. Muscle activation pattern hip arthroplasty patients in walking. Res Sports Med 2004;12:191-9.

Winter DA. ABC of balance during standing and walking. Waterloo: Waterloo Biomechanics; 1995
Wylde V, Blom AW, Whitehouse SL, Taylor AH, Pattison GT, Bannister GC. Patientreported outcomes after total hip and knee arthroplasty: comparison of midterm results. J Arthroplasty 2009;24:210-6.

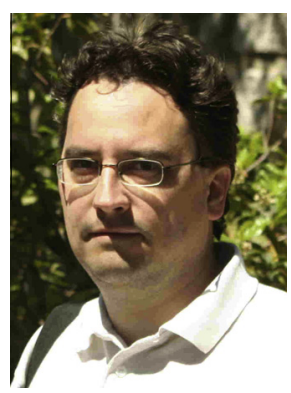

Gergely Holnapy MD, orthopaedic surgeon, traumatologist. Graduated from the Faculty of General Medicine of Semmelweis University of Medical Science in Budapest in 1999; passed special examination of orthopaedy-traumatolgy in 2006. Main research areas: conservative and operative treatment/rehabilitation of injuries, motion analysis. Published a number of special articles, methodology guides, and conference lectures in the past years.

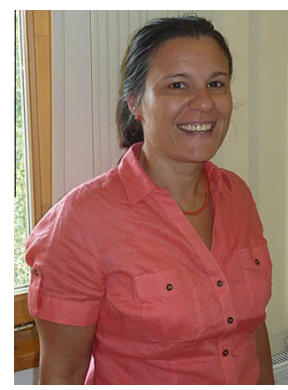

Rita Kiss PhD, Dr. habil, associate professor at Budapest University of Technology and Economics. Graduated from the Faculty of Civil Engineering of the Technical University of Budapest as qualified civil engineer in 1991. She got her PhD degree in 1997, and was conferred the degree of Dr. habil at Budapest University of Technology and Economics in 2008, in the subject of Biomechanics. Main research area: analysis of human motion mechanics. Member of several domestic and international scientific and educational bodies/committees. Published a number of special articles, methodology guides, and conference lectures in the past years. 